\title{
Benchmarking initiatives in the water industry
}

\author{
R. Parena*and E. Smeets** \\ *Azienda Acque Metropolitane Torino S pa, C orso XI Febbraio 14, 10152 Torino, Italy \\ ** W aterleiding Maatschappij Limburg, PO Box 1060, 6201 B B Maastricht, The Netherlands
}

Abstract $C$ ustomer satisfaction and service care are every day pushing professionals in the water industry to seek to improve their performance, lowering costs and increasing the provided service level. Process B enchmarking is generally recognised as a systematic mechanism of comparing one's own utility with other utilities or businesses with the intent of self-improvement by adopting structures or methods used elsewhere. The IW A Task Force on B enchmarking, operating inside the Statistics and Economics Committee, has been committed to developing a general accepted concept of $P$ rocess $B$ enchmarking to support water decision-makers in addressing issues of efficiency.

In a first step the Task F orce disseminated among the $\mathrm{C}$ ommittee members a questionnaire focused on providing suggestions about the kind, the evolution degree and the main concepts of B enchmarking adopted in the represented C ountries. A comparison among the guidelines adopted in The N etherlands and Scandinavia has recently challenged the Task F orce in drafting a methodology for a worldwide process benchmarking in water industry.

The paper provides a framew ork of the most interesting benchmarking experiences in the water sector and describes in detail both the final results of the survey and the methodology foc used on identification of possible improvement areas.

Keywords C omparison; experiences; methodology; process; survey; Task Force

\section{Introduction}

The increased involvement and demands of the public, and the awareness by utility leaders that performance improvement is essential make water and wastewater utilities highly motivated in being efficient, effective and competitive.

Nevertheless, the context operated by public utilities is, in many countries around the world, highly characterised by absent competition and market pricing.

In practice, the fact that water is an essential resource for individual and social life as well as for the environment and ecology determines a natural offering monopoly and limits the extent to which it can be regarded and priced simply as another economic good.

An effective market economy requires prices to be openly known in order to offer signals, both to customers and producers, about the demand for and the availability of goods in a competitive environment. Vice versa, the absence of competitive market pricing makes it impossible directly to determine the quantity, the quality and the level of the service provision to be supplied.

Market competition rises indeed when a water company makes, with other companies, a tender for the renewal or for a new contract of water service, provided by a prevailing position granted by its know how and know why.

However, when the bid is concluded, the market adjustment is hardly reconciled with the rules Vilfredo Pareto stated. At the same time the targets of service continuity, quality, extension and cost savings that the regulation systems of the water market fix to the operators can't be resigned.

Therefore, it seems virtually impossible to neatly apply the performance evaluation mechanism considering the presence of many "explanatory factors", which also vary with 
the variety of management types, regulations and environment, affecting the company efficiency and effectiveness.

On the other hand, market rules require players be constantly adapted to the business environment and both customer satisfaction and service care are every day pushing professionals in the water industry to seek to improve their performance by lowering costs, enhancing revenue collection and increasing the level of provided service.

\section{About benchmarking}

Peer comparisons and suitable reactions undoubtedly allow best competitors to be ahead of changes provided by proprietary know how. Nevertheless it seems that many difficulties exist in setting up well defined reference points that allow, particularly for water companies, an objective evaluation of the company performance.

When, at the end of the 1970s, Fuji conquered the photocopiers market with better quality products and lower prices, Xerox was forced to critically review its products and production costs by adopting the Japanese philosophy of "Dantotsu": gaining the best of the bests by learning, assimilating and improving.

A Chinese saying goes "If we are not changing the way, we could end just where we are going to" and to see how the organisation can do more with less is the typical approach to implement Benchmarking initiatives.

The American Water Works Association has defined Benchmarking as "a systematic process of searching for best practices, innovative ideas, and highly effective operating procedures that lead to superior performance and then adapting those practices, ideas, and procedures to improve the performance of one's own organisation".

Usually benchmarking activities require the definition of potential operations and processes to improve and the negotiation of partnership arrangements in order to collect homogeneous and comparative data and to observe living examples of superior performance suggesting new perspectives toward best practices.

In the interest of fairness it has to be noted that, despite the growing popularity, the benefits of benchmarking for many organisations are difficult to be realised in practice.

Water and wastewater industries made attempts to create standard or high level performance indicators indeed. At the beginning this was not endorsed enthusiastically by utilities because of the difficulty of normalising data and concerns about their use. Also utilities are not using common accounting definitions, which makes comparison difficult. However, some successful exercises and, above all, the commitment of the International Water Services Association, and now of the International Water Association, in boosting the continuous improvement in managing water services enhanced the emphasis in this area.

Metric Benchmarking is a quantitative comparative assessment of company performance, normally operated by Performance Indicators, that enables comparisons among peer utilities, and by which trending information and target levels of performance can be established too. Costs are investigated with regard to the organisational function they relate to and the accounting criteria leading to allocation of the traditional figures are the key reference point.

Process Benchmarking is a mechanism of identifying specific work procedures to be improved by emulation of external examples of excellence that can be set as the best standard. Costs are investigated with regard to the activities developed inside the processes crossing the organisational functions and the criteria leading to allocation in the activity based cost accounting figures are the key reference.

In these terms, by metric benchmarking, areas of under performance requiring changing the way things are done can be identified, whilst by process benchmarking a vehicle for 
achieving this change and the pursued improvement can be imported from other best practice partners.

In short, process benchmarking implies finding out how others do business, whether they are more efficient than we are and, if so, whether we can understand and use their methods to our advantage. Consequently, potential benchmark operations and processes have to be identified and partnership arrangements negotiated in order to collect comparative data and to observe living examples of superior performance.

In a further step, relations and correlation between processes or functions have to be investigated in order to check achievable costs saving, since these experiences generate a new perspective toward best practices and facilitate the development of innovative solutions to process problems.

The basic importance of defining the measures, to be used in performance assessment and comparisons, and that of mapping in detail the selected processes, to compare in an homogeneous context, is stemming from the above.

\section{Benchmarking developed experiences}

Some important experiences (Xerox model inspired) have been so far developed to test Benchmarking procedures, both metric and process, in a water context.

The Philadelphia Water Department case study, undertaken with the American Water Works Association Research Foundation, has been focused on learning how to conduct process benchmarking within the water industries and to specifically improve operations by gaining control over the system for recording customers reports about leaks and repair works.

The Syndicate Benchmarking worked out in New South Wales (Australia) by seven municipal government organisations aimed at assessing the benefits of a syndicate benchmarking for local government councils, at preparing guidelines and making recommendation, on how councils might undertake water services benchmarking.

In the United Kingdom, Severn Trent Water worked out a benchmarking study focused on assessing the best opportunities for maximising the benefits coming from a 4.5 million pounds expenditures budget, ten years referred and privatisation process connected. The study was specifically oriented to benchmark the management of projects, of know how, of resources and of investments return.

OFWAT, the industry regulator in England and Wales, has approached the comparative efficiency assessment to gain a key determinant of the level of charges from 2000 to 2005 as more demanding targets will be assumed in post - 2000 water charges for companies judged to be least efficient. International comparative exercises have moreover been carried out to allow independent comparisons between the privatised water companies in England and Wales and water enterprises operating, under different regulatory regimes, in Sydney and in the metropolitan area of Perth (Australia).

The Scandinavian "6 Cities Group" is co-operated by the cities of Copenhagen, Helsinki, Oslo, Stockholm, Gothenburg and Malmo. It focuses on quality, environment and costs aiming at designing a well defined structure of performance indicators, which should facilitate international comparisons among the involved members.

The "New Benchmarking System" (formerly COCLUWA) involves about the $85 \%$ of Dutch water service. It compares performance indicators to grant transparency for drinking water sector in The Netherlands, according governmental request, and provides management information for controlling and influencing drinking water pricing.

The European Bank for Reconstruction and Development has recently appointed the Water Research Centre, from UK, to carry out a benchmarking exercise focused on investigating target levels and performance measures in selected water companies operating in 
Western Europe, and comparing them with water and wastewater enterprises in Poland. The study will provide the Bank with comparative reference data as a basis to determine the relative and operational performance efficiencies of potential Bank borrowers and to set yardstick performance targets for borrowers against industry best practice.

The American Water Works Association developed the voluntary "QualServe Program" aimed at helping the North American utilities in achieving total quality performance. "Self assessment" and "Peer review" procedures are used to examine 15 areas of utility performance and design an agenda for possible quality improvements whilst the "Benchmarking Clearinghouse" provides information, services and tools targeted to water and wastewater facilities.

In USA the Western Regional Water Utilities Benchmarking Group (WRWUBG), originally established in early 1996, grouped 14 West Coast utility organisations researching structure and practices they could engage in to make benchmarking meaningful for themselves and other utilities. Using the benchmarking process framework developed by the American Productivity and Quality Centre (APQC) of Houston, Texas, 12 business processes were described for each utility, data were collected, best practices identified, performance indicators established, comparison made and practices documented to identify so improvement opportunities for each component of distribution system assets.

The Italian Federation of Public Water Utilities promoted, in 1998, a Benchmarking project aimed at setting up a general framework, at analysing the operating processes of major activities and at identifying performance reference standards and possibly define the best practices. The Benchmarking Club is currently operated by 14 member-companies and an independent consultant collects data. The identification of areas with potential for performance improvement, the suggestion about organisational structures and related control systems more apt to overcome performance limitations and the validity of Benchmarking in boosting the rediscussion of roles, functions and procedures are the results of the first two years of activity.

\section{International water association benchmarking initiatives}

Since late 1997 the International Water Services Association has been underlining the real interest and feasibility of developing a general accepted structure of Performance Indicators (P.I.) able to provide decision-makers with an overall perception of the utility performance as a strong support in making strategic choices. The Task Force on Performance Indicators, operating inside the Operation \& Maintenance Committee, is going to release the final document on these PIs.

Also the International Water Services Association has then achieved the importance of a deeper analysis of Benchmarking procedures, possibly deputed to develop a general accepted concept and a methodology to widely use in practice, in order to boost the improvement in quality and efficiency.

The Task Force on Benchmarking, operating inside the Statistics and Economics Committee, was committed to develop, in strict co-operation with the Task Force on Performance Indicators, a general accepted concept of Process Benchmarking and a methodology to widely use in practice to support water decision makers in addressing issues of efficiency.

The International Water Association is now continuing and strengthening these intentions.

At the end of 1998 the Task Force on Benchmarking disseminated, mainly among the Committee members, 29 questionnaires focused on providing suggestions about the kind, the evolution degree and the main concepts of Benchmarking adopted in the represented 
Answers were obtained from Austria, Belgium, Cyprus, Denmark, England, Finland, France, Germany, Hungary, Italy, Luxembourg, Netherlands, Scotland, Spain, Sweden, Switzerland, Hong Kong, Malaysia, New Zealand, North America (U.S.A. and Canada), and South Africa. A general score of about $76 \%$ represents a good result of answering; nevertheless, the absence of some important countries (not only from Europe) makes the framework not so wide as was expected.

Two topics were investigated through the questionnaire. About the first, dealing with PIs

- in 15 countries (the $68 \%$ of received answers) a set of generally accepted PIs is adopted;

- in France only one water company is going to achieve some performance results about its water activities within 1999;

- in the other countries few water companies individually adopt the practice of using PIs, but this does not seem to be a generally accepted behaviour in the country;

- where adopted, PIs are periodically performed (once a year) and in seven countries (Austria, Denmark, Spain, Sweden, New Zealand, North America and South Africa) only the selected companies are concerned, whilst in four countries (Finland, Hungary, Italy and Scotland) all the companies are involved;

- in eleven countries (Austria, England, Finland, Hungary, Italy, Netherlands, Scotland, Sweden, Malaysia, New Zealand and North America) the practice of using PIs is suggested or boosted by national organisations: in all cases by National Water Companies Associations, but in Finland and Italy even by governmental institutions;

- only in Austria, England, Italy, Scotland, Sweden, Malaysia and North America, PIs are used even in providing external institutions with water industry data, whilst the general behaviour points out an internal use of PIs. A very widespread diffusion can be observed in Sweden, whilst in Austria and Italy the Regulatory bodies are mainly concerned; Trade and Consumers Associations are typically addressed in England, Scotland and North America;

- "Production" and "Distribution" (both around 77\%) and "Financial and Economics" (73\%) are the processes / activities typically covered. Customer service (50\%) is far away;

- PIs results are widened in six countries (Austria, Hungary, Italy, Scotland, Sweden and Malaysia), disseminated among the selected companies in the other six (Cyprus, England, Finland, Germany, Netherlands and North America) and taken as proprietary in the remaining countries;

- comparisons, mainly examined/discussed at middle and top levels (59\% both), give rise to standard reference points or to improvement targets in thirteen of the checked countries $(64 \%)$.

About the second topic, more specifically related to Process Benchmarking:

- a general voluntary inclination to Benchmarking initiatives can be observed, both as current involvement (59\%) and as the 1999 project (9\%). In the Netherlands and Scotland some obligations (by National Organisations) to take part in these initiatives exist. In the first country, legal ruling is expected as a recommendation;

- the number of the involved water companies ranges from 2 (South Africa) to 183 (Austria) with an average of 24, extreme values excluded;

- excluding Denmark and Finland, these Benchmarking initiatives are generally dedicated to water industry, both with regard to some selected companies (40\%) and to all the companies in the country $(40 \%)$;

- as observed, about PIs "Production", "Distribution" and "Financial and Economics" are the most covered processes/activities, but "Customer Service" is attracting more relevant attention (73\%). "Customer orientation" $(53 \%)$ is consequently sharing with 
"Environment" (47\%) and "Water Quality" (73\%) the panorama of the aspects covered by B. projects;

- in some cases other processes/aspects, like "Planning" (in the Netherlands), "Network operation methodologies" (in Sweden), "Level of service and operational performance" (in England), "Engineering and Purchasing processes" (in Italy), "Organisational, Technical and Market processes" (in Germany), are concerned with Benchmarking.

- Benchmarking projects have been initiated:

- by the National Water Associations in Austria, Finland, Italy, Netherlands and Switzerland (project 1999);

- by companies initiative in Belgium (project 1999), Denmark, England, Germany (even with Bundesverband der Gas und Wasserwirtschaft input), Scotland, Sweden and North America;

- by an independent consultant initiative in New Zealand;

- and data collection is operated:

- by the National Water Associations in Austria, Finland, Netherlands, Scotland and Switzerland (project 1999);

- by one (every) company included in the project in Denmark, England, Germany and Sweden;

- by an independent consultant in Italy, New Zealand and South Africa;

\section{A methodology for a world-wide process benchmarking}

According to the results of the above mentioned survey the Benchmarking Task Force of the IWA Committee on Statistics and Economics is now committed to set up a generally accepted methodology able to allow water companies in benchmarking their processes all over the world.

The project is underpinned by the positive experiences of the Nordic countries, grouped in the "6 Cities Group", and The Netherlands and aims at providing a valid tool to compare all over the world the Utilities' performances and at identifying and isolating areas for possible improvement.

Water quality, Service, Environment, Finance and Efficiency were identified as the four main areas to be considered to gain a complete and balanced picture of the Utility's performances.

Water quality expresses the level in meeting the (statutory) requirements. Some acute health-related, non-acute health-related, consumer-related and process-related parameters are accurately selected for.

The extent in meeting customers' expectations defines the quality of the Service as perceived both by clients and utility management. Service aspects have to be considered in terms of service dimensions, most relevant activities and types of customer contact.

From one hand, consumption in resources and direct emissions and, from the other hand, efforts in the field of nature conservation express the systematic and qualitative approaches to the environmental management.

Cost and revenues allocated in the statements at the end of the fiscal year provide a lot of data for Finance and Efficiency monitoring according to various models of analysis and levels of detail.

Nevertheless, the Scandinavian and Dutch experience confirmed a lot of difficulties in providing comparable data on quality, service and environmental aspects. So, the project adopted a more practical approach mainly focusing on the key financial aspects of drinking water sector. The extension to water treatment and waste disposal can be a second step exercise.

The starting point has been the process-based and well defined classification of 
activities, which gives rise to costs and revenues to be investigated through a reduced number of selected key official figures.

A possible administration of the database and presentation of reports via the Internet was examined as well as the direct involvement of IWA.

Four cost categories were then distinguished:

- Taxes (including levies and administrative charges directly related to the drinking water supply and environmental taxes);

- Capital costs (including the cost of loan capital - interest - as well as the cost of shareholders' equity - dividends and profit retaining or sharing - and so making the analysis independent of the way the company finances its activities);

- Depreciation and amortisation (of all tangible and intangible assets, valued at historical cost. A model's correction occurs when the asset are current cost evaluated);

- Operational costs (directly related to operations).

The operational costs are fitted in the process model that distinguishes four key figures. Within the production and distribution processes a further distinction is made between investment activities and operational activities.

The production process includes all activities (including the facilities' design, construction, operation and maintenance) related to water collection and water protection areas from tapping to carriage and raw water treatment. Water quality monitoring is included too.

The distribution process includes all activities aimed at guaranteeing an uninterrupted supply of sufficient quantities of drinking water of a good and consistent quality such as the design, construction, operation and maintenance of mains.

The sales process includes all customer services from meter readings and data processing to further billing, paying and contacts handling.

The supporting process includes all support activities related to planning and strategic policy definition, personnel recruiting and management, financial and economic affairs, services, consumable and warehouse management.

Basically the financial model is "closed" being all costs and revenues as they appear in the annual financial statements. In the interest of correctness a distinction is then made between revenues related to drinking water supply and other revenues included in the model as "negative costs".

A restricted number of reasonably simple data (fewer than 50), consistent with closed definitions and process descriptions, will implement the model in order to produce, when processed, stock or unit comparable key information and ratios.

The need for homogeneity with metric benchmarking exercises developed by the IWA Task Force on Performance Indicators and the intention that duplication should be avoided indicate that the adoption of a similar converted currency and converging definitions should be strongly recommended.

The total income from drinking water and the connected operating profit can give a general overview about revenues, particularly when the framework of comprehensive charges for drinking water supply expressed in currency $/ \mathrm{m}^{3}$ on an annual basis and standard consumed volumes related is added to them.

Similarly, unit costs (expressed in currency $/ \mathrm{m}^{3}$ sold and currency/connection subscribed) can give a meaningful comparable and synthetic framework when showing their allocation among the above mentioned four categories and processes.

The most usual ratios such as solvency ratio, cashflow ratio, average credits period ratio and return on shareholders equity ratio complete and even summarise the financial key aspects.

To gain a more balanced picture of the utility's performance and given the detected 
difficulties in obtaining detailed information on quality, service and environmental aspects some other "volumetric and dimensional" data implement the financial model.

These data, most of which were even considered among metric benchmarking parameters (so confirming connections and inter-relations between the two approaches), affect the average number of employees (expressed in full time equivalent), the number of connections, the volumes of drinking water globally abstracted (according to different sources) and sold, the length of mains, the total investments and the water balance.

\section{Conclusions}

Whether we like it or not we are always being benchmarked by customers, by the financial markets and even by potential employees.

At the beginning of a new century all the water companies are looking for business in the non-regulated sector where potential clients have a huge choice of companies to pick from and leader competitors are provided by facilities management expertise.

It is important to embrace benchmarking positively rather than just take reactive measures: the point is to be alert and to want to learn because the true benefit of Benchmarking lies in its ability to help in adding value.

For this purpose the Benchmarking Task Force of the IWA Statistics and Economics Committee aims at learning from on going experiences and wider discussion in order to more deeply analyse and tune the proposed methodology so that the general concept can be accepted and meaningful testing developed.

\section{References}

Achttienribbe, G., Homer, V. and Parena, R. (1998). Different approaches to charging water: the IWSA comparisons. European water policy, IX $\mathrm{H}_{2}$ Obiettivo 2000, Venezia, Italy.

Cabrera, E. jr. (1999). Benchmarking de procesos mejora de la gestion de abastecimientos de agua potable. Benchmarking course, Grupo Mecanica de fluidos, Departamento de Ingenieria Hidraulica y Medio Ambiente, University of Valencia, Spain.

Gale, D. (2000). The use of benchmarking and performance measures as utility improvement strategies, Wat. Supply 18(12) 652-657.

Helland, B. and Adamsson, J. (1999). Performance benchmarking among 6 cities in Scandinavia. Internal report, Oslo, Norway.

Huberts, J. and Smeets, E. (2000). Performance indicators and benchmarking evaluation of company efficiency: the system employed by WML in The Netherlands, Wat. Supply 18(12) 646-651.

Larsson, M., Smeets, E. and Troquet, I. (1999). Towards a worldwide benchmark in the water industry. Report to the IWA Committee on Statistics and Economics, London, UK.

OFWAT (1999). Comparing the performance of England \& Wales water \& sewerage companies with Sydney Water and Water Corporation Western Australia. Report August 1999, OFWAT, Birmingham, UK.

Paralez, L. (1999). Utility benchmarking on the West Coast. AWWA Journal, 91(11), 65-71.

Parena, R. (1999). The IWSA benchmarking initiatives, Performance Indicators for water and sewage services: an actual tool for better management and public regulation, Hydrocontrol International workshop, Cagliari, Italy.

Parena, R. and Sanna, F. (2000). The Benchmarking Club of Italian water services: first results of an experience started in 1998, Wat. Supply 18(112) 641-645.

Performance Benchmarking for Water Utilities (1996). American Water Works Association Research Foundation, Denver, USA.

VEWIN (1999). Water inzicht - Interne rapportage. Internal report, Rijswijk, The Netherlands. 